\title{
Assessing local health needs in primary care: understanding and experience in three English districts
}

\author{
Joanne Jordan, John Wright, John Wilkinson, Rhys Williams
}

\begin{abstract}
Background-Assessing the health needs of a local population has been promoted as a key component in effective targeting of healthcare services and quality improvement. The understanding and experience of assessing health needs in general practice were investigated in three English districts.
\end{abstract}

Aim-To identify the issues surrounding the potential for assessing health needs in primary care.

Method-Postal survey of 347 general practices in three health authorities. Telephone interviews with a random stratified sample of 35 general practitioners.

Results-Although most practices identified assessing health needs as important, it is clear that this identification was typically based on an understanding of assessing needs as primarily focused on individual patient care, based on clinical priorities and involving practice held data. Most practices had not undertaken local consultation, whatever their understanding of assessing health needs. The few practices which had completed population oriented, proactive assessment of needs considered it to have led to tangible improvements in clinical or practice management. Overall, there was apparent confusion over the nature and purpose of assessing needs, although the principled aims and objectives of a population oriented, proactive component to primary care were generally upheld. The need for additional resources and support was identified. In four out of the five cases where specifically population based assessment of health needs had been undertaken, the local public health department had been involved.

Conclusion-The value of the concept of assessing health needs in primary care holds considerable uncertainty and ambivalence. The findings from this study show that any attempts to promote assessing needs into primary care which focus either primarily or exclusively on the provision of "education" are unduly simplistic. More fundamental questions about the perceived relevance and opportunities for assessing health needs should be considered if primary care groups are to meet future commissioning challenges. (Quality in Health Care 1998;7:83-89)

Keywords: health needs; assessment; primary care
Introduction

Understanding the needs of patients is one of the most important principles underlying the improvement in quality of care received by patients. Indeed, recent research suggests that such understanding of patients' needs overwhelms all other factors deemed relevant to quality improvement. ${ }^{1}$ Whereas the assessment of health need is a relatively new concept in the developed world where health services have traditionally been demand led, it is established practice in the developing world where effective use of scarce resources has long been an urgent priority. $^{23}$ Increasing demands on limited resources in western countries has highlighted the international importance of undertaking rigorous assessments of health needs.

In the United Kingdom assessing the health needs of a local population has been increasingly promoted as a key component in effective targeting of healthcare services and appropriate use of health resources. ${ }^{45}$ In particular, the focus on assessing needs has come about as changing primary care and public health responsibilities have centred attention on the delivery of population health care at a local level. ${ }^{67}$ Throughout all of these changes the importance of assessing health needs in securing a system of health care led by evidencebased needs has been affirmed. Originally a requirement of purchasing and commissioning authorities, ${ }^{8}$ assessing needs has more recently come to be seen as integral to the process by which primary care responds to local and national priorities in the promotion of effective and equitable care (box 1). ${ }^{9}$ In this context especially, the idea of local consultation has been upheld. ${ }^{10}$

Although various definitions of assessing health needs exist, ${ }^{11-14}$ the following gives an overall view: a systematic, population oriented, proactive and wide ranging process of identifying health needs and appropriate interventions which have the potential to maintain, improve, and prevent ill health (box 2). ${ }^{15}$ Although many publications consider the theoretical, practical, and ethical issues associated with assessing health needs, little empirical evidence on understanding and uptake within primary care in the United Kingdom exists. With the definition of assessing health needs already outlined as a basis of research, this study sought to rectify this shortfall while providing a comprehensive review of the issues surrounding the potential for the development of assessing needs within primary care.
Accepted for publication 8 April 1998 
Within the British National Health Service (NHS) the responsibilities for purchasing and providing health care are divided. District health authorities are responsible for commissioning health services on the basis of health needs identified within a population (typically around 500000 people). These services are provided by local health service providers including hospitals, primary care teams, and community health organisations.

Also, primary care teams have had an increasing role in commissioning health services, initially through being allocated individual budgets (fundholding) and more recently in collaborating with other local practices in primary care groups to decide on the allocation of resources (locality commissioning by primary care groups). This has led to an increased responsibility in assessing local needs.

Box 1 Purchasers and providers in the NHS.

Assessment of health needs is the systematic method of identifying unmet health and healthcare needs of a population and making changes to meet these unmet needs. It involves an epidemiological and qualitative approach to determining priorities which incorporates clinical and cost effectiveness and patients' perspectives. This approach must balance clinical, ethical, and economic considerations of need, that is what should be done, what can be done, and what can be afforded.

Box 2 Definition of assessment of health needs.

\section{Method}

The research was carried out in 1996 in three health authority districts in northern England chosen to represent differing sociodemographic populations. Leeds is an industrial conurbation with a population of around 1000 000; North Yorkshire is a predominantly rural area, with a population of about 700000 and an economy based on agriculture, tourism, and some light industry; finally, Bradford is also an industrial centre, with a population of about 500 000, including a large (15\%) south Asian population.

\section{QUESTIONNAIRE STUDY}

A draft questionnaire was developed with questions chosen by the authors (appendix). The questions were suggested and ranked by each author and then discussion held until consensus was reached about which questions should be included. After piloting, the questionnaire was sent to the first named general practitioner in every practice throughout the three districts (a total of 347 practices). The general practitioner was asked to discuss the questionnaire with his or her colleagues at the next practice meeting. Instructions asked that respondents answered questions with all relevant practice activity in mind. A reminder letter was sent after one month. The question- naire asked about previous experience and practical application of assessing needs, as well as areas of interest for future assessment, including perceived skills and support required. We deliberately did not provide a definition of assessing health needs nor did we ask respondents to provide such a definition as we anticipated the possibility of wide variation in understanding and did not wish to prejudice findings. To keep the questionnaire relatively brief we did not ask for particulars relating to what clinical or management improvements had resulted from assessing needs; this area was explored in greater detail during the telephone interviews (box 3).

With SPSS, descriptive analysis established percentage ratings for all specified variables, whereas bivariate $\chi^{2}$ analysis identified significant cross tabulations. In particular, we were interested in differences in responses between practices according to health authority, numbers of partners, and fundholding status.

INTERVIEW STUDY

To explore further the issues involved, JJ selected a random sample of practices (stratified for fundholding and numbers of partners)

(1) Understanding assessment of health needs, including:

(a) What it means?

(b) Its relevance to general practice?

(2) Nature and extent of assessment of health needs carried out within the practice, including:

(a) What assessment has been carried out?

(b) If any assessment carried out has resulted in improvements to quality of health or health care provided? What improvements? Why, or why not?

(3) Which areas or topics are considered the most important to assess and why?

(4) View on the support or skills required by the practice so that assessment of health needs can be undertaken?

(5) Nature or extent of communication occurring between the practice and local health authority, including:

(a) Could this communication be improved? If so, in what ways?

(b) Does the local health authority have a valid part to play in primary care? Why or why not? If yes, what is that role?

(6) Views on future of role of primary care, including:

(a) What would be of most benefit to the practice in its work?

Box 3 Telephone interview guide. 
Table 1 Characteristics of responding practices in comparison with overall sample

\begin{tabular}{lcc}
\hline & $\begin{array}{l}\text { Respondents } \\
n(\%)\end{array}$ & $\begin{array}{l}\text { Overall } \\
n(\%)\end{array}$ \\
\hline $\begin{array}{l}\text { Fundholding } \\
\text { Partners (n): }\end{array}$ & $54(34)$ & $117(35)$ \\
$1-2$ & $49(32)$ & $146(42)$ \\
$3-4$ & $48(32)$ & $114(32)$ \\
$\geqslant 5$ & $36(24)$ & $86(24)$ \\
\hline \multirow{2}{*}{ Complete information on these variables was not available for } \\
$19(13 \%)$ of the respondents.
\end{tabular}

in each health district for telephone interview. An interview guide was developed considering issues similar to those covered in the questionnaire. However, the open ended nature of interview questions provided respondents with the opportunity to discuss at length these and other issues that they considered pertinent to assessing needs. Given the apparent diversity of approaches to assessing health needs the telephone interviews were considered particularly important as they allowed discussion around perceived meaning and relevance.

Although the practices were randomly selected we had no control over the individual general practitioners who chose to undertake the telephone interview. All of the 35 general practitioners subsequently interviewed were therefore self selected, some of whom had a stated interest in assessing health needs. Interviews were recorded and transcripts were analysed for recurrent themes in issues identified as relevant to the development of assessing health needs in primary care. This allowed a systematic analysis of content, as well as the investigation of relations between specified practice characteristics and identified priorities.

\section{Results}

QUESTIONNAIRES

There was an overall response of $44 \%$ (152), ranging from $32 \%(42 / 131)$ in Leeds to $61 \%$ $(72 / 118)$ in North Yorkshire. No difference was found between fundholding status or numbers of partners and response rate (table 1).

Of responding practices $45 \%$ (68) considered assessing health needs to be very important, $46 \%$ (70) described it as fairly important, and $7 \%$ (10) designated it not important. Twenty six per cent (39) of practices stipulated that they had carried out assessment of needs. The activities most often cited were: audit with medical records; the use of questionnaires primarily to investigate priorities identified within the practice - such as asthma-and other general health screening activity. Most (25/39) of these practices considered that such work had led to tangible improvements in clinical or management practice. Larger practices (five or more partners) were significantly more likely to have carried out population oriented, proactive assessment of needs than smaller practices (four or less partners, $\chi^{2}, \mathrm{p}<0.005$ ).

Priority areas and support required

Table 2 shows the areas or topics that practices considered most important to examine when assessing needs. Practice priority was most
Table 2 Most important areas to examine when assessing local health needs by frequency

\begin{tabular}{lcc}
\hline Area of needs assessment & $\begin{array}{l}\text { Survey } \\
(n)\end{array}$ & $\begin{array}{l}\text { Interviews } \\
(n)\end{array}$ \\
\hline Health promotion & 35 & 19 \\
Social needs & 34 & 10 \\
Mental health & 25 & 13 \\
Cardiovascular disease & 23 & 8 \\
Specific diseases & 22 & 4 \\
$\quad$ (osteoporosis, breast cancer, etc) & & \\
Elderly & 17 & 6 \\
Alcohol and drug misuse & 15 & 6 \\
Practice demography & 15 & 8 \\
Carers or carer support & 11 & 2 \\
Diabetes & 10 & 2 \\
Asthma & 9 & 4 \\
Reproductive health & 6 & 1 \\
Rehabilitation & 4 & 0 \\
Other & 57 & 18 \\
&
\end{tabular}

Table 3 Areas of support required by practices by the top three rank positions

\begin{tabular}{lrrr}
\hline Area of support & \multicolumn{1}{l}{1} & \multicolumn{1}{l}{2} & \multicolumn{1}{l}{3} \\
\hline Guidance on suitable topics & 28 & 4 & 7 \\
Surveys of practice population & 18 & 16 & 7 \\
Improving practice information systems & 17 & 10 & 6 \\
Analysis of practice data & 5 & 15 & 17 \\
Public consultation strategies & 4 & 16 & 12 \\
Guidance on effectiveness & 4 & 15 & 20
\end{tabular}

often said to be the basis of selection (56). Most practices (113) considered that they would require support to undertake assessment of needs. Table 3 summarises the top three areas of support identified. Also, 11 practices mentioned extra resources as the support required.

Twenty eight per cent (42) of practices stated that they had consulted local people about health needs and how they should be met. The most common method was by patient questionnaire. Little detail was provided on the topic or area of consultation, but where stated such consultation focused on priorities identified by the practice - such as patient satisfaction with practice services.

There were no significant differences in responses provided by practices according to health authority and fundholding status or numbers of partners.

\section{INTERVIEWS}

Although all 35 practices interviewed were eventually able to offer an interpretation of assessing health needs, it is notable that 15 initially expressed confusion over its meaning, with 11 of these explicitly asking for clarification before providing a response. Only a few practices spontaneously associated assessing needs with the identification of specifically unseen or unmet need. Of those practices which endorsed this idea of population oriented, proactive assessment of health needs, most did so after the idea had been introduced (as one of several possible approaches) by the researcher.

With the above definition of assessing health needs, 11 of the general practitioner representatives stated that no such activity had been carried out, either because it was considered irrelevant or subordinate to routine primary care activity, or because it was considered an 
inappropriate use of resources. Several practices highlighted the futility of such activity given the lack of resources available to provide an effective response.

The remainder of practices considered that they had carried out work which could be described as assessing health needs, with most citing general preventitive activity, including screening, audit, and clinic work. Typically, this activity was suggested on the grounds that it constituted effective preventive (proactive) primary health care or dealt with patient subpopulations identified as at risk. These properties were seen as more relevant than others which might challenge the definition of assessing needs-such as the fact that the audit or screening work was uniformly inspired by clinical priorities and dealt with need which was to some degree at least already identified.

\section{Improvements in quality of care}

Practice representatives were overwhelmingly of the opinion that such work had led or would lead to significant improvements in the quality of care provided. One general practitioner concentrated on an audit of coronary heart disease in which all patients identified as having angina were put on aspirin as part of a longer term programme of care. Another described the development of an at risk register of patients with a family history of breast, ovarian, and stomach cancer, with the ultimate aim of putting in place a comprehensive screening programme. Finally, one general practitioner focused on an initiative in which computer records were used to identify patients with asthma particularly at risk-for example, those on oral steriods or requiring hospital admission - to effectively monitor their practice based care. In such cases it was clear that existing information-for example, practice based records-was being used to improve the management of patient groups identified on the basis of clinical priorities - for example, current medical evidence.

Only five of the general practitioner representatives had conducted specifically population oriented, proactive assessment of needs, with four having been involved in initiatives facilitated by the local public health department. Depending on the stage of assessing needs reached, all considered the work to have either already led to improvements in the quality of health and health care enjoyed by patients or to be leading to such improvement in the near future. One general practitioner representative described the relevance of this form of assessing needs in terms of its ability to promote "purchase for health, not for illness". In this context, the practice had embarked on a three stranded programme consisting of: the development of a practice profile based on the previous 5 years of computer records; the development of district profile, consisting of locality data drawn from various sources; finally, ongoing local consultation, initially in the form of rapid appraisal and, in the longer term, through the setting up of a consultative health panel, comprising local residents.

Perhaps the most interesting comments came from those representatives who understood that assessing health needs involved a population oriented proactive approach but whose practices had not engaged in such activity. Among this group there was widespread acknowledgement of the relevance of assessing needs to improve the quality of care provided. These representatives associated assessing needs with: appropriate targeting of finite resources; effective planning of services to meet need; and exposing the areas in which practices were failing to provide adequate clinical care. Several representatives were particularly explicit on this point, stressing how a population oriented proactive approach inevitably broadened the scope of primary care knowledge, thereby encouraging the provision of care more directly relevant to patient need.

\section{Local consultation}

Most practices had either failed to implement any means of local consultation or had limited such consultation to surveys considering priorities decided within the practice. The practices involved in public health department initiatives had all been involved in more comprehensive local consultation. This experience encouraged a greater appreciation of the value of including patient understanding of need, primarily as a means of showing unidentified and, importantly, otherwise unidentifiable need.

\section{Routine health data}

Nearly half (16) of the representatives interviewed considered computer stored information to be an integral part of assessing needs, an understandable response given its association with audit, screening, and general health promotion activity. A smaller number (7) commented on the unreliability or limited relevance of computer records, either due to inconsistencies in or incompleteness of data, or because assessing needs was understood as going beyond existing practice or clinical knowledge.

\section{Practice priorities and resource requirements} All representatives identified important areas of assessing needs primarily on the basis of practice priorities (summary in table 2). A consensus view upheld the need for additional resources if assessing needs was to progress within general practice. These were targeted as follows: to train existing staff-for example, in compiling and manipulating computer databases or in the design and analysis of patient surveys - or to employ extra staff to undertake activity related to assessment of needs. Overall, departments of public health were considered to be in an advantageous position to deliver population based assessment of needs, which could be based on aggregate primary care based data.

\section{Non-responders}

We included several (17) non-responders in the sample of practices for telephone interview to identify the reasons behind the relatively low response rate to the questionnaire. Two explanations were most often provided: firstly, that the practice simply did not have time to 
respond; and secondly, that the practice either did not know about, or was not interested in, assessing health needs. When this evidence was combined with the fact that most practices continued to associate assessing needs with individually oriented reactive care, as well as with the fact that 11 out of the 35 practices interviewed asked for some form of clarification of the phrase assessing health needs, it is clear that the concept is surrounded by considerable uncertainty and some ambivalence.

\section{Discussion}

Taken overall, the research findings suggest that assessing health needs remains poorly understood and relatively untried within primary care. Not only did practices possess varied ideas about its nature (including holistic care, health promotion, screening, and audit, as well as more population oriented, proactive care) doubts were raised about the value, relevance of, and opportunities for assessing needs. The fact that many practice representatives associated such activity with departments of public health again suggests widespread doubt about the role of primary care in assessing health needs. However, the fact that those practices which had undertaken collaborative primary care and public assessment of health needs wholeheartedly endorsed the process suggests that such collaboration may provide one possible way of encouraging assessment of needs based on primary care.

EFFECTIVENESS OF ASSESSING HEALTH NEEDS

Most of those practices which had carried out specifically population based, proactive assessment of needs considered either that it had led to tangible improvements in clinical or management practice or would do so in the forseeable future. Of these, most had plans for further similar work. This suggests that when such assessment of needs is undertaken, it is perceived as worthwhile. The apparent lack of interest in consulting local people is significant, especially in the light of a recent national emphasis on involving patients in healthcare decision making. ${ }^{7}$

\section{RESOURCE REQUIREMENT}

A common theme uniting all interviews was the need for additional resources for practice based assessment of needs to progress. Although practices did make recommendations as to how these resources might be targeted, little detail was provided. In the absence of a clear understanding of the nature and purpose of assessing health needs it is possible that any extra resources would be absorbed into general administrative or clinical work. For example, practice nurses were mentioned several times to develop a role to assess needs, but this was usually associated with screening or health promotion activity. Also, there was a common assumption that many of the answers to understanding local health needs lay in the rich source of data stored, either actually or potentially, in the practice computer system. In the light of the widespread association between assessing needs and audit or preventive activity the emphasis on practice held data is understandable but it does suggest that the potential for more proactive, innovative assessment of needs may be limited.

The recent Audit Commission report highlighted a lack of assessing health needs in fundholding practices. ${ }^{16}$ Our research suggests that this is characteristic of primary care as a whole. Moreover, much of what is currently being undertaken as assessing health needs is not a population based, proactive assessment. Although collaboration between primary care and public health was mentioned by respondents as a possible way forward, and indeed, was present in most cases in which a proactive population approach had been adopted, it would be naive to think that such collaboration is either possible or appropriate on a nationwide basis. It cannot be assumed that most departments of Public Health have the necessary expertise to handle both the quantitative and qualitative aspects of assessing health needs, let alone the time to resource it.

Consequently, general practice needs to begin to consider the resources available closer to home, in particular, the skills and experience brought in by health visitors and community nurses. Not only does the formal literature on assessing health needs stress the benefits of involving the entire primary healthcare team at all stages, but some of the most successful examples have been based on just this approach. Also, other people - such as those involved in community (health) projects or qualitative researchers-should be considered.

Whatever the particular arrangements, the problem of lack of time and other resources identified by practices remains. Although collaboration between departments of public health and primary care may bring about some transfer of appropriate knowledge and skills, it deals less with the problem of lack of time and other resources identified by practices. The availability of such resources would therefore seem to be an essential consideration if primary care professionals are to be asked to assume added responsibility, especially where this involves time consuming consultation or the use of data not immediately to hand. Greater efforts could therefore be made to integrate support for assessing health needs with that currently available for audit activity and postgraduate education. Also, the examples of successful collaboration between primary care and public health departments at a district level might usefully be applied to collaboration between practices in a locality. Whatever the scale, a team approach which enables a sharing of workload and resources either within or between practices will help in achieving a feasible approach to assessing health needs within primary care.

\section{RECOGNISING THE IMPORTANCE OF ASSESSING} HEALTH NEEDS

Discussion of possible approaches to assessing health needs does not consider more fundamental issues about its perceived value within primary care. In the United Kingdom the new Labour government has committed itself to 
ensuring access to treatment according to "need and need alone". Primary care commissioning groups will be required to plan, commission, and monitor local health services to meet identified local needs. However, this does not necessarily translate into acceptance of the benefits of conducting population based assessment, particularly where this involves activity which is fundamentally different in both its focus and aims to traditional practice based care. If the results of assessing needs are to lead to changes in services to consider the needs identified, then adequate attention must be given to planning and implementation. This includes the need for the setting of clear objectives, the involvement of relevant stakeholders, and the agreement of criteria for prioritising need. However, the problems associated with such planning and implementation have been highlighted. ${ }^{17}$ Current funding arrangements for primary care not only fail to acknowledge the resource implications but make responses through development of service initiatives difficult. If assessing needs is to be effective then the responsiveness of these funding arrangements must be improved. This is particularly important given the underlying endorsement of the aims and objectives of assessing health needs uncovered by our research. In the absence of the necessary infrastructural support, it is likely that such principled advocacy will continue to lack effective expression.
1 Smith R. Understanding customer's needs is the key to improvement. BMF 1997;314:1301.

2 Vaughan JP, Morrow RH. Manual of epidemiology for district health management. Geneva: World Health Organisation, 1989.

3 de Konig K, Martin M. Participatory research in health. Issues and experiences. Johannesburg: Zed Books, 1996.

4 Secretary of State for Social Services. Public health in England: the report of the committee of inquiry into the future development of the public health function. London: Her Majesty's Stationary Office, 1988.

5 Department of Health. Working for patients. London: Her Majesty's Stationary Office, 1989

6 Evans D. Setting the agenda: health commissions, public health and primary care. Critical Public Health 1994;5:415.

7 Graffy J, Jacobson B. General practitioners and public health doctors: sharing common goals? $\mathrm{Br} \mathcal{F}$ Gen Pract 1995;45:640-2.

8 Department of Health. The NHS and Community Care Act. London: Her Majesty's Stationary Office, 1990.

9 National Health Service Executive. An accountability framework for GP fundholding: towards a primary care-led NHS. work for GP fundholding: towards a
Leeds: NHSE, 1994. (EL (94) 54)

10 National Health Service Management Executive. Local voices, the views of local people in purchasing for health. London: Department of Health, 1992.

11 Robinson J, Elkan R. Health needs assessment, theory and practice. London: Churchill Livingstone, 1996.

12 Gillam S, Murray S. Needs assessment in general practice. London: Royal College of General Practitioners, 1996. (Royal College of General Practitioners Occasional Paper 73.)

13 Murray S, Graham LJC. Practice bases health needs assessment: use of four methods in a small neighbourhood. BMF 1995;310:1443-8.

14 Stevens A, Gabbay J. Needs assessment needs assessment. Health Trends 1991;23:20-3.

15 Jordan J, Wright J. Making sense of health needs assessment. Br f Gen Pract 1997;48:695-6.

16 Audit Commission. What the doctor ordered. Fundholding: the main report. London: Her Majesty's Stationary Office, 1996.

17 Ruta DA, Duffy MC, Farquharson A, et al. Determining priorities for change in primary care: the value of practicebased needs assessment. Br f Gen Pract 1997;47:353-7. 


\section{Appendix: Assessing health needs in general practice}

Unless otherwise stated please answer the following questions by placing a tick in the box that best represents your view.

1. Do you believe that it is important to assess the health needs of your practice population?

Very important $\square \quad$ Fairly important $\square \quad$ Not important

2. Has your practice carried out any local assessment of health needs?

No $\square \quad$ GO TO Q4 Yes $\square$

If YES, please describe briefly the area(s) assessed and method(s) of assessment.

3. Did the assessment of health needs result in any tangible changes in clinical or management practice?

No

Yes $\square \quad$ Not sure $\square$

4. Do you have any current plans for the practice to carry out future local health needs assessment?

No $\square \quad$ Yes

5. What areas or topics would your practice consider the most important to examine when assessing local health needs? Please list in order of priority.

1.

2.

3.

6. On what basis have you identified these priorities? Please tick all that apply.

National priority $\square \quad$ Regiona/district priority $\square \quad$ Practice priority

Other (please state)

7. Would your practice require support to undertake assessment of local health needs?

No

GO TO Q9

Yes $\square$

8. What support would your practice require? Please select only the highest three priorities and rank in order of importance from 1 to 3 , where $1=$ most important and $3=$ least important.

Guidance on suitable topics

Analysis of practice data

Surveys of practice population

Public consultation strategies

Improving practice information systems

Other (please state and rank)

Guidance on effectiveness

9. Has your practice consulted local people about health needs and how they should be met?

No

Yes $\square$

If YES, please describe briefly the area(s) and method(s) of consultation.

10. Does your practice have any future plans to consult local people about health needs and how they should be met?

No

Yes $\square$

11. Please use the following space to comment on other local health needs assessment issues you consider to be important.

Thank you very much for completing the questionnaire.

Practice stamp:

The postal questionnaire. 